\title{
BMJ Open What factors hinder ethnic minority women in rural China from getting antenatal care? A retrospective data analysis
}

\author{
Bo Liu, ${ }^{1,2}$ Duorui Shi, ${ }^{3}$ Wei Wang, ${ }^{4}$ Lei Nan, ${ }^{5}$ Bibo Yin, ${ }^{5}$ Chongyi Wei, ${ }^{6}$ Aga Emu, ${ }^{7}$ \\ Haiqun Zhou, ${ }^{7}$ Wuha Wazha, ${ }^{8}$ Jianming Zhu, ${ }^{9}$ Shumei Wang, ${ }^{1}$ Wei Ma ${ }^{1}$
}

To cite: Liu B, Shi D, Wang W, et al. What factors hinder ethnic minority women in rural China from getting antenatal care? A retrospective data analysis. BMJ Open 2019;9:e023699. doi:10.1136/ bmjopen-2018-023699

- Prepublication history for this paper is available online. To view these files, please visit the journal online (http://dx.doi org/10.1136/bmjopen-2018023699).

$\mathrm{BL}$ and DS contributed equally.

Received 30 April 2018

Revised 08 July 2019

Accepted 12 July 2019

Check for updates

(C) Author(s) (or their employer(s)) 2019. Re-use permitted under CC BY-NC. No commercial re-use. See rights and permissions. Published by BMJ.

For numbered affiliations see end of article.

Correspondence to

DrWei Ma; weima@sdu.edu.cn

\section{ABSTRACT}

Background Mother-to-child transmission (MTCT) is one of the main transmission routes of HIV, and the probability of MTCT can be dramatically reduced with comprehensive interventions. In southwest and western regions in China, the level of development in rural areas is relatively backwards and retains some original features, which also increases the difficulty of controlling infectious diseases. The Liangshan Prefecture started the prevention of MTCT programme in 2009. However, the implementation of the programme is not ideal, and the coverage of HIV testing is still low. Many Yi (local major ethnicity) women did not take antenatal care (ANC) and just gave birth to their babies at home for a variety of reasons.

Methods Women with pregnancy history in the last 5 years were recruited from two townships based on cluster sampling. Face-to-face interviews were conducted to collect data. Descriptive analysis was performed to describe demographic characteristics, history of pregnancy and ANC uptake, knowledge of and attitudes towards ANC. Multivariable analysis was used to identify factors associated with uptake of ANC

Results Among 538 women who completed the questionnaires, $77.9 \%$ knew that ANC was necessary during and after pregnancy. However, only $24.2 \%$ actually accessed ANC. Almost all women (94.6\%) expressed their willingness to receive ANC for pregnancy but barriers towards actual uptake of ANC existed including shyness, lack of independence and unavoidable cost. Multivariate analysis showed that no experience of living outside of Zhaojue for more than 6 months, higher number of births, not knowing the necessity of ANC during pregnancy and not knowing the government's promotion policies for ANC were associated with lack of ANC uptake.

Conclusion Although ethnic minority women in rural Liangshan expressed strong intention to use ANC, actual uptake of ANC was low. Knowledge of ANC and HIV prevention for MTCT should be improved among this population, and efforts should be made to help them overcome barriers to accessing ANC.

\section{INTRODUCTION}

\section{Background}

HIV can be suppressed by combination antiretroviral therapy (ART) consisting of
Strengths and limitations of this study

- The subjects of this study were selected from health service provider, the recipient and the hub of them (the key figure in a family), which enriched the research perspective and made information acquisition and research results more comprehensive and objective.

- We only selected women of childbearing age who had pregnancy history in the last 5 years from two towns of Zhaojue, so maybe the findings are not generalisable to all the women of childbearing age in the rural area.

- Due to the mode of survey administration (interviewer-administered face to face), social desirability bias might be introduced.

- It may overestimate the uptake of antenatal care (ANC) because this study only focused on the uptake of ANC of the respondents within the whole 5 years and ignored whether they accepted ANC during the most recent pregnancy.

- Our HIV-related questions were not mother-to-child transmission or prevention for mother-to-child transmission specific, so future studies should consider HIV-related questions that are more relevant to the concerns and needs of pregnant women.

three or more antiretroviral drugs. Elimination of prevention for mother-to-child transmission (PMTCT) of HIV is now considered a realistic public health goal and an important component of a comprehensive HIV prevention package. There were approximately 36.9 million people living with HIV at the end of 2017 with 1.8 million people becoming newly infected in 2017 globally. Fifty-nine per cent of adults and $52 \%$ of children living with HIV were receiving lifelong ART in 2017. ${ }^{12}$

A comprehensive approach to PMTCT programmes is promoted by The WHO, which includes: (1) precluding new HIV infections among women of reproductive age; (2) avoiding accidental pregnancies 
among HIV-infected women; (3) preventing HIV vertical transmission from an HIV-infected mother to her child; and (4) providing applicable treatment, care and support to HIV-infected mothers, their children and families. ${ }^{3}$ China has been starting on PMTCT since 2003 and achieved similar progress as other parts of the world. ${ }^{4}$ However, in some remote rural areas, especially regions resided by ethnic minority groups, PMTCT still faces significant challenges. For example, Liangshan Yi Autonomous Prefecture in Sichuan Province, which is situated on a major drug trafficking route of the Golden Triangle, is one of the areas that has the highest HIV infection rate in the past few years. ${ }^{5-9}$ A study reported that HIV prevalence was $4.4 \%$ among rural residents in two of the most affected counties in Liangshan prefecture in 2009, Butuo and Zhaojue. ${ }^{7}$ Furthermore, an early study conducted among HIV-positive pregnant women in the prefecture in 2004 found that $7.0 \%$ of their infants were tested HIV positive, ${ }^{9}$ which is significantly higher than the national average. Although overall rate of mother-to-child transmission (MTCT) dropped from $10.5 \%$ in 2008 to $5.5 \%$ in 2013 (unpublished data), MTCT of HIV is still a serious public health concern in this area due to lack of HIV testing, barriers to accessing treatment and care, and poverty and illiteracy among the population.

Antenatal care could provide opportunities to identify undiagnosed cases as well as conduct PMTCT among HIV-positive women. Liangshan Prefecture began to execute PMTCT programme at ANC clinics and hospitals since 2009. In addition to providing regular pregnancy-related check-ups, ANC also includes free HIV testing. However, coverage of PMTCT especially uptake of HIV testing remained low. One of the reasons for such low coverage was that about one-third of local women delivered their babies at home rather than in the hospitals. ${ }^{9}$ Furthermore, even fewer pregnant women accessed ANC before delivery. A study reported that $62 \%$ of pregnant women in the prefecture had fewer than five ANC visits during pregnancy, while $26.0 \%$ never used any ANC. ${ }^{10}$ Therefore, in order to improve the effectiveness of the PMTCT programme, access and uptake of ANC need to be improved substantially.

The study area, Zhaojue County, is an underdeveloped county with one of the highest HIV infection rates in Liangshan. ${ }^{7}$ In addition to the PMTCT programme, the China/UNICEF Conditional Cash Transfer project, which provides incentives for pregnant women to use $\mathrm{ANC}$ and deliver in hospitals, has also been implemented in Zhaojue. However, proportions of women who access ANC and have child delivery in hospitals are still below the average level in the prefecture. In order to encourage more women to access ANC and improve coverage, it is necessary to identify factors that may promote or hinder use of ANC among this vulnerable population.

\section{Objectives}

The objectives of this study were to describe knowledge, acceptability actual uptake of ANC and to identify factors associated with lack of ANC attendence among women of childbearing age in Zhaojue County, Liangshan, China.

\section{METHODS}

\section{Setting and participants}

The survey was conducted in Zhaojue County of Liangshan Prefecture in December 2014. The county is located in east-central Liangshan, southwestern Sichuan Province, with an area of 2700 square kilometres and a population of 308300 . The main $(97.9 \%)$ local population is the Yi, residing in 47 towns and 269 villages. ${ }^{11}$

First, we purposively selected two townships that both have larger population and hospitals that provide ANC. Then we divided the villages within the two townships into two layers based on the distance between the villages and the township hospital. The average distance from the villages in the two layers to the township hospitals is $8 \mathrm{~km}$ and $15 \mathrm{~km}$, respectively. One village close to the hospital and one far away from the hospital were randomly selected from each township. All eligible women in the selected four villages were invited to participate in the study. Inclusion criteria included: (1) female; (2) aged 49 years or under; (3) had a pregnancy history in the last 5 years; and (4) having resided in Zhaojue County for at least 6 months. The sample size is calculated by the equation $\mathrm{N}=\mathrm{Z}^{2} \mathrm{P}(1-\mathrm{P}) / \mathrm{d}^{2}$, and $\mathrm{Z}=1.96, \mathrm{~d}=0.05$. The hospital delivery rate in Liangshan Yi Autonomous Region in 2013 was about 56\%, so $\mathrm{p}=0.56$ and $\mathrm{N}=378$. As cluster sampling was conducted, in order to reduce sampling error, we increased the sample size by $50 \%$. So, the sample size is 567 .

\section{Study instrument and data collection}

A structured questionnaire was developed by local health experts based on literature review, formative research and pilot test. The information collected included: (1) demographic and household characteristics of participants, including age, income, education, ethnicity, occupation, marital status, age of the participant's husband and family size; (2) history of pregnancy, including number of pregnancies, number of births, and whether participants accessed ANC during their pregnancies; (3) whether they know ANC is necessary, ANC is free, where to get ANC and what ANC includes; (4) willingness to utilise ANC measured by a series of yes/no questions, facilitators of and barriers to accessing ANC; and (5) whether they have heard of AIDS and knew someone who was HIV positive.

Interviewers were five local women who were proficient in both Yi (local language) and Mandarin. They were trained by School of Public Health, Shandong University before investigation to ensure study protocol was followed. On account of the general low educational level of some respondents, oral informed consent was obtained from each of them before the face-to-face interview. For respondents who do not know how to write their own names, the investigator signed on their 
behalf with their consent. This study is a cross-sectional study that does not involve clinical trials. In consideration of that most of the respondents are illiterate, the ethics committee approved this procedure. The trained investigators directly inquired about the participants and explained to them the thoughts involved in the questions. After confirming that the participants understood the questions, interviewers filled out the questionnaire according to interviewees' answers. Investigators conduct investigations at the village committee, using the 'Prenatal Health Survey Form for Women of Childbearing Age' to conduct investigations. Some respondents may not be present, so researchers need to go to their home for face-to-face investigation until we collect enough data.

\section{Data management and statistical analysis}

All the data were double entered with Epidata 3.1, and discrepancies were checked against the raw data. Data analysis was performed with SPSS V.21.0. Descriptive analysis was used to describe demographic characteristics, history of pregnancies and ANC-related variables. To identify independent correlates of ANC uptake, univariate analysis was first conducted through $\chi^{2}$ tests comparing characteristics of women who accessed ANC during their pregnancy versus those who did not. Variables with $p$ values $<0.05$ in the univariate analysis were eligible for entry into the multivariable logistic regression model, where adjusted OR and 95\% CI were calculated accordingly.

\section{Patient and public involvement}

No patients were involved in the development of the research question nor the design of the study. The Zhaojue County Maternal and Child Health Hospital has processed the research results into science knowledge and informed local villagers through several publicity in 2018. In this process, the staff informed the villagers that both men and women should pay attention to antenatal care, and the government will bear most of the costs.

\section{RESULTS}

\section{Demographic characteristics}

A total of 547 women with pregnancy history in the past 5 years (1 January 2010 31 December 2014) were approached and 538 valid questionnaires were collected, with a response rate of $98.4 \%$. The mean age of participants was 35.6 years, and $7.0 \%$ of them were less than 25 years of age. Most participants $(86.2 \%)$ were illiterate. Almost half $(45.1 \%)$ had 4-5 family members, while $87(16.4 \%)$ had $1-3$ and family members. More than half $(56.2 \%)$ had 3-4 births. Women in the $\leq 25$-year-old group had the highest proportion of antenatal care at $48.6 \%$. The proportion of participants in the 25-35 age group and the 35-45 age group who participated in antenatal care was $28.6 \%$ and $17.5 \%$, respectively. For the $>45$-year-old group, only $9.2 \%$ ever took ANC. In the age group with spouse $\leq 25$ years, the participation rate of ANC was $44.4 \%$. With the increase of the spouse age group, the participation rate decreased, which was $30.6 \%, 20.3 \%, 11.1 \%$. The higher the level of education, the higher the percentage of prenatal examinations. The percentage of women who attended primary and junior high school examinations $(35.3 \%$ and $33.3 \%)$ was significantly higher than the 22.2\% who did not attend school. Among women of childbearing age who have lived for more than half a year outside of Zhaojue, the proportion of people who have had antenatal care is $63.9 \%$, which is significantly higher than that of women who have not lived outside of Zhaojue $(23.1 \%)$. A percentage of 34.5 of women with three or fewer family members ever took $\mathrm{ANC}$, and the proportion of people who too ANC for $4-5$ and $\geq 6$ was $26.3 \%$ and $18 \%$, respectively. In addition, women who give fewer births have a higher rate of participation in prenatal care. Among those with 0-2 births, $33.7 \%$ have received ANC, but in those with 4-5 births and 6 or more, this proportion is only $24.3 \%$ and $4.4 \%$ (table 1).

\section{History, knowledge of and attitude towards ANC}

Almost all participants (94.6\%) reported that they were willing to use ANC during pregnancy. However, just under a quarter $(24.2 \%)$ had ever received it. The majority $(77.9 \%)$ thought ANC was necessary during and after pregnancy, $84.5 \%$ thought it was necessary to give birth in hospitals and $83 \%$ also knew that ANC and delivery in hospitals were free. However, almost half $(45.2 \%)$ did not know what ANC included. Almost all of the participants (97.4\%) heard of AIDS and more than half $(54.7 \%)$ knew someone who was HIV infected. Compared with those who ever used ANC, participants who did not were significantly more likely not to have known that ANC was necessary during pregnancy $(27.5 \%$ vs $5.4 \%, \mathrm{p}<0.001)$, not to have known delivery should be in hospital $(17.8 \%$ vs $8.4 \%$, $\mathrm{p}<0.05)$, not to have known ANC and delivery in hospitals are all free $(19.4 \%$ vs $9.3 \%, \mathrm{p}<0.005)$ and not to have known government encourages ANC $(39.1 \%$ vs $24 \%$, p<0.005) (table 2).

\section{Independent correlates of lack of ANC uptake}

In multivariable analysis, women who did not know that ANC during pregnancy was necessary $(\mathrm{OR}=4.056$, 95\% CI 3.021 to 14.706 ) and those who did not know about government's support policy of ANC ( $\mathrm{OR}=2.033$, 95\% CI 1.292 to 3.195) were less likely to use ANC. Women who never lived outside of Zhaojue for more than 6 months (OR=5.882, 95\% CI 2.874 to 12.048$)$ and those who had five or more deliveries (OR=10.989, $95 \%$ CI 3.311 to 37.037 ) were more likely to have not used ANC (table 3). 
Table 1 Differences in demographic characteristics between participants who used ANC versus those who did not

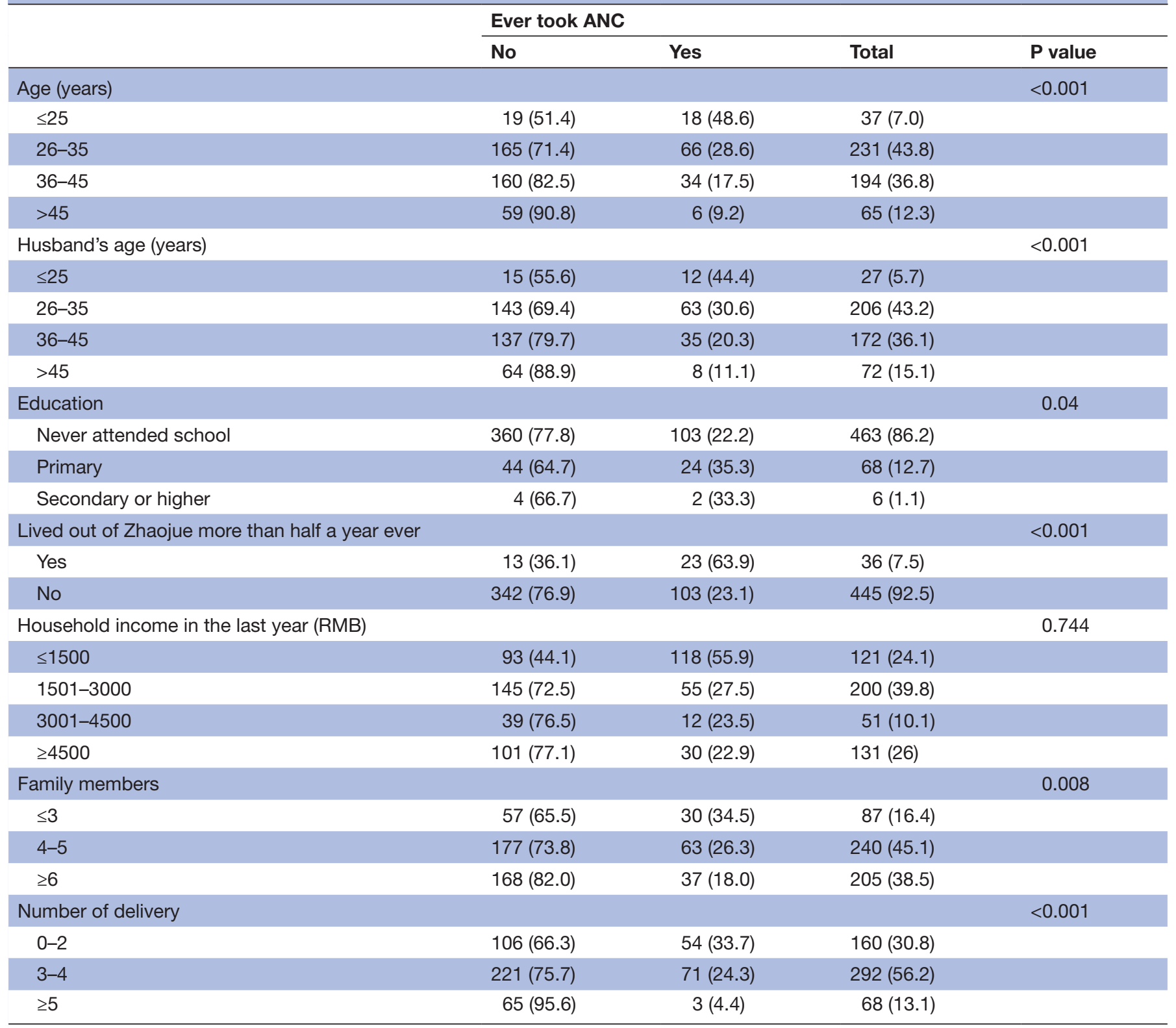

ANC, antenatal care.

\section{Facilitators and needs assessment of ANC}

When asked about who can influence their decisions of accessing ANC, almost half reported Village Women Federation $(47.9 \%)$, followed by husbands $(43.8 \%)$ and parents-in-law $(34.7 \%)$. The most cited reasons for not using ANC were shyness (33.3\%), incapability of going without company $(27.3 \%)$ and cultural custom $(15.2 \%)$. In terms of facilitators of ANC, the most popular responses were reimbursement of transportation (73.8\%), improved education of ANC among women (64.2\%) and linking ANC to issuance of birth certificates $(51.9 \%)$. About a third of participants $(30.9 \%)$ thought 50 RMB (about US\$8) for ANC was acceptable and $23.3 \%$ thought $100 \mathrm{RMB}$ was acceptable; however, $22.1 \%$ was unwilling to pay (table 4 ).

\section{DISCUSSION}

In this study, we investigated knowledge about, acceptance and uptake of ANC among women of childbearing age in an ethnic minority area of China. We also explored factors associated with lack of ANC uptake among these ethnic minority women. We found that majority of participants knew that ANC was free and that it was necessary to use antenatal care during pregnancy, and most of them were willing to use ANC. However, less than a quarter had ever accessed ANC, which is much lower than reported by previous studies. In 1998, The National Health Service Surveys reported that $81 \%$ of women used ANC, meanwhile, $76 \%$ women in rural areas accessed ANC during 1998-2000. ${ }^{12} 13$ There were a few possible reasons for the low uptake of ANC found in our study. First, the study 
Table 2 Differences in knowledge of ANC, HIV and PMTCT between participants who used ANC versus those who did not

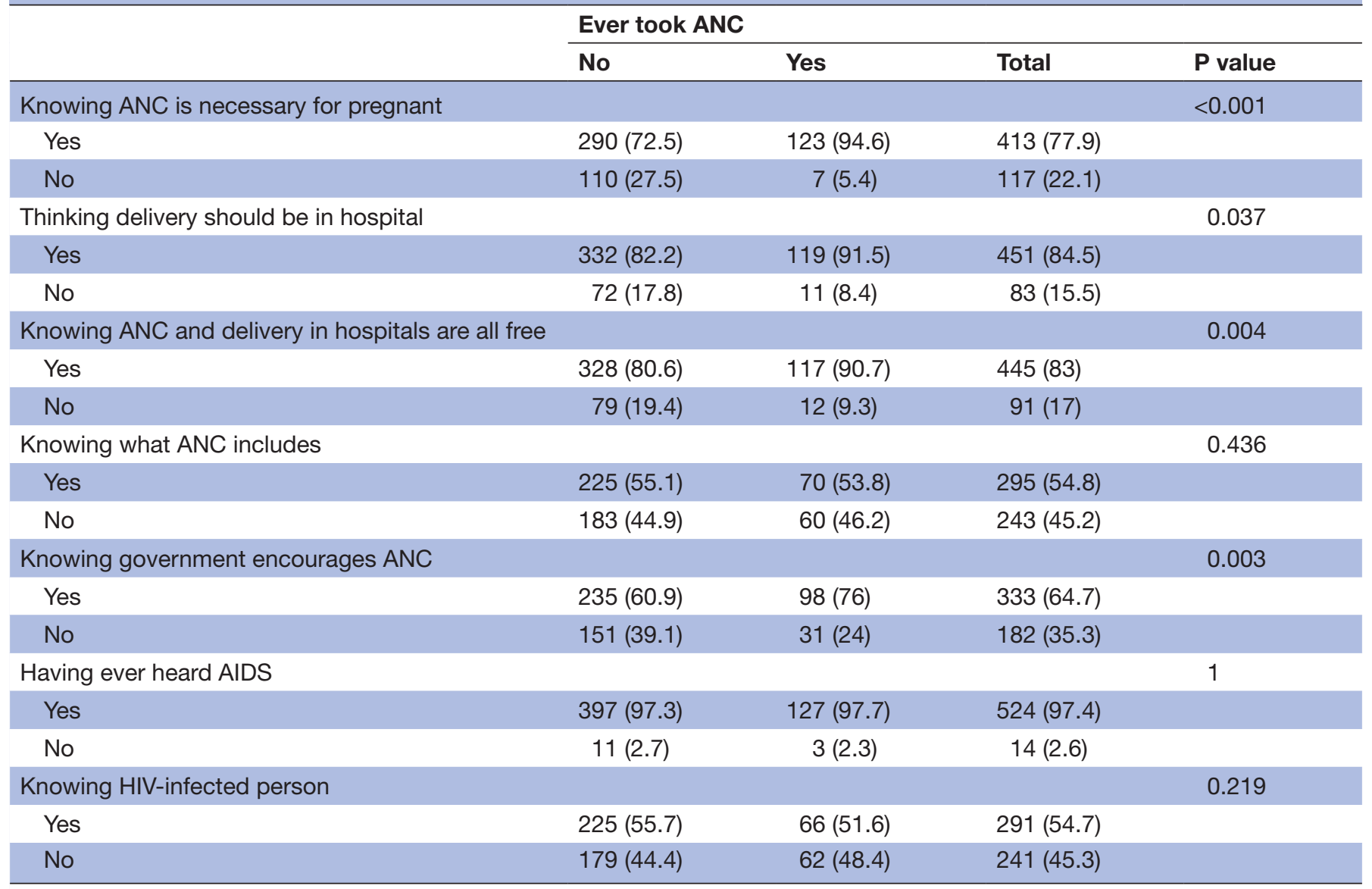

ANC, antenatal care; PMTCT, prevention for mother-to-child transmission.

area is undeveloped, many women do not know about the government's policy and they worry about the spending as well as transportation issues. Second, many women in this area are illiterate and non-independent (they said they were not able to go without company). In addition, the cultural custom of not talking about pregnancy and just delivering at home also hinder those pregnant women from taking ANC. Third, the strong intention to use ANC reflected current attitudes among participants, while the actual uptake of ANC covered many previous pregnancies. In recent years, due to the implementation of the PMTCT programme in the area, the proportion of Yi women who delivered in hospitals had increased substantially. However, local governments only started to encourage and support ANC access a couple of years before the current survey. There were some informational and educational materials of ANC being distributed, but most women in the rural areas of Zhaojue were illiterate.

We found that women who understand the need for ANC during pregnancy or who understand the government's support policies for ANC are more likely to have received ANC. We also found that having had five or more deliveries was negatively associated history of taking ANC. Women with more pregnancies tended not to take ANC for two possible reasons: (1) these women were older and less educated, thus their knowledge of ANC was relatively poor and they may have no ability to communicate with healthcare professionals. (2) They might think that they had successfully experiences of delivering babies therefore it is no need to care about ANC. The results of our study were similar to studies in other developing countries. For example, in the systematic review by Simkhada et al, factors associated with the utilisation of ANC were: education level of pregnant women and their spouses, health service accessibility, cost, family income and so on. They also found that the attitude towards pregnancy could impact the utilisation of ANC, and there was an inverse correlate between the previous pregnancy and the utilisation of ANC. ${ }^{14}$ Some studies conducted in China also had similar findings. For example, Liu and Ceng conducted studies individually in 2007 and 2010, and and they found factors associated with the intention and uptake for pregnant women to take ANC could be summarised into three categories: (1) demographic characteristics of pregnant women and their spouses such as low education level, older age and low economic level; (2) number of children; and (3) policies such as birth control leading the worry about being punished even forced abortion. ${ }^{15} 16$

Surprisingly, we found that having ever heard of AIDS and knowing someone who was HIV-infected were not 
Table 3 Multivariable analysis of independent correlates associated with having not used ANC

\begin{tabular}{|c|c|c|}
\hline \multirow{3}{*}{ Age (years) } & \multicolumn{2}{|c|}{ Having not used ANC } \\
\hline & \multirow[t]{2}{*}{ OR } & $95 \% \mathrm{Cl}$ \\
\hline & & \\
\hline & 1 & \\
\hline $26-35$ & 4.464 & (1.170 to 4.785$)$ \\
\hline $36-45$ & 4.464 & (2.119 to 9.346$)$ \\
\hline$>45$ & 9.346 & (3.236 to 27.027$)$ \\
\hline \multicolumn{3}{|l|}{ Husband's age (years) } \\
\hline$\leq 25$ & 1 & \\
\hline $26-35$ & 1.815 & (0.804 to 4.098$)$ \\
\hline $36-45$ & 3.135 & (1.346 to 7.299$)$ \\
\hline$>45$ & 6.410 & (2.227 to 18.519$))$ \\
\hline \multicolumn{3}{|l|}{ Education } \\
\hline $\begin{array}{l}\text { Secondary or higher } \\
\text { school }\end{array}$ & 1 & \\
\hline Primary or lower & 2.748 & (1.967 to 3.165$)$ \\
\hline \multicolumn{3}{|c|}{ Lived out of Zhaojue more than half a year ever } \\
\hline Yes & 1 & \\
\hline No & 5.882 & (2.874 to 12.048$)$ \\
\hline \multicolumn{3}{|l|}{ Number of deliveries } \\
\hline $0-2$ & 1 & \\
\hline $3-4$ & 1.585 & (1.038 to 2.421$)$ \\
\hline$\geq 5$ & 10.989 & (3.311 to 37.037 ) \\
\hline \multicolumn{3}{|c|}{ Is ANC for pregnancy necessary? } \\
\hline Yes & 1 & \\
\hline No & 4.056 & (3.021 to 14.706$)$ \\
\hline \multicolumn{3}{|c|}{ Is giving birth in hospitals necessary? } \\
\hline Yes & 1 & \\
\hline No & 2.151 & (0.884 to 5.235$)$ \\
\hline \multicolumn{3}{|c|}{ Knowing ANC and delivery in hospitals are all free } \\
\hline Yes & 1 & \\
\hline No & 2.347 & (1.235 to 4.464$)$ \\
\hline \multicolumn{3}{|c|}{ Knowing government encourages ANC } \\
\hline Yes & 1 & \\
\hline No & 2.033 & (1.292 to 3.195$)$ \\
\hline \multicolumn{3}{|l|}{ Family size } \\
\hline $1-3$ & 1 & \\
\hline$\geq 4$ & 2.062 & (1.290 to 3.745$)$ \\
\hline
\end{tabular}

ANC, antenatal care.

associated with uptake of ANC. A possible reason is that women might not be aware of HIV testing services provided by ANC or that HIV was not one of the top health concerns during their pregnancy, and knowledge of HIV and perceived threat of HIV were not sufficient to motivate them to get themselves tested during ANC.
Table 4 Facilitators and needs assessment of ANC among participants

\section{Items}

Frequency (\%)

People who affect the decision of ANC

\begin{tabular}{lc} 
Spouse & $232(43.8)$ \\
Parents-in-law & $184(34.7)$ \\
Parents & $31(5.8)$ \\
Family & $5(0.9)$ \\
Village doctor & $105(19.8)$ \\
Village Women Federation & $254(47.9)$ \\
Others & $108(20.4)$ \\
No idea & $10(1.9)$ \\
Refuse to answer & $2(0.4)$ \\
People who support to use ANC & \\
Spouse & $287(53.9)$ \\
Parents-in-law & $253(47.6)$ \\
Parents & $122(22.9)$ \\
Family & $7(1.3)$ \\
Village doctor & $236(44.4)$ \\
Village Women Federation & $382(71.8)$ \\
Others & $27(5.1)$ \\
No idea & $6(1.1)$ \\
People who oppose to use ANC & \\
Spouse & $9(1.9)$ \\
Parents-in-law & $10(2.1)$ \\
Village doctor & $18(3.8)$ \\
Village Women Federation & $25(5.2)$ \\
Others & $427(89)$ \\
No idea & $12(2.5)$ \\
Refuse to answer & $8(1.7)$ \\
\hline Resons for objetng &
\end{tabular}

Reasons for objecting to using ANC

\begin{tabular}{lc}
$\begin{array}{l}\text { Cultural custom } \\
\text { Incapability of going for ANC without } \\
\text { company }\end{array}$ & $9(27.3)$ \\
$\begin{array}{l}\text { Shyness } \\
\text { Cost of transportation }\end{array}$ & $21(33.3)$ \\
$\begin{array}{l}\text { Others } \\
\text { Refuse to answer }\end{array}$ & $10(30.3)$ \\
$\begin{array}{l}\text { How to promote the usage of ANC } \\
\text { Carrying out health education to } \\
\text { women }\end{array}$ & $5(15.2)$ \\
$\begin{array}{l}\text { Carrying out health education to } \\
\text { spouses }\end{array}$ & $100(18.9)$ \\
$\begin{array}{l}\text { Getting reimbursement for } \\
\text { transportation }\end{array}$ & $391(73.8)$ \\
$\begin{array}{l}\text { Issuing birth certificate based on ANC } \\
\text { Others }\end{array}$ & $275(51.9)$ \\
$\begin{array}{l}\text { No idea } \\
\text { Money willing to pay for ANC }\end{array}$ & $27(5.1)$ \\
\hline
\end{tabular}

Money willing to pay for ANC

Continued 


\begin{tabular}{lc}
\hline Table 4 Continued & Frequency (\%) \\
\hline Items & $110(22.1)$ \\
\hline Unwilling to pay anything & $154(30.9)$ \\
$<50$ & $118(23.7)$ \\
$<100$ & $99(19.9)$ \\
$<200$ & $15(3.0)$ \\
$<500$ & $1(0.2)$ \\
$\geq 500$ & \\
\hline Favourable accompanying person taking & \\
ANC & $162(39.2)$ \\
\hline Husband & $82(19.9)$ \\
\hline Mother or mother-in-law & $16(3.9)$ \\
\hline Family & $140(33.9)$ \\
\hline Women's association of village & $1(0.2)$ \\
\hline Village doctor & $12(2.9)$ \\
\hline Others
\end{tabular}

ANC, antenatal care.

Findings from our study suggest that future efforts to increase uptake of ANC and improve PMTCT should focus on the following aspects: (1) improve knowledge of ANC among pregnant women, especially among those with low education or illiterate. For example, instead of text-based educational materials, picture-based materials should be distributed. In addition, mini-dramas or plays demonstrating the importance and benefits of ANC could be conducted at community events; (2) improve accessibility of ANC, which may involve infrastructure construction, provision of user-friendly services and so on. In this study, many participants did not know places where ANC is offered, and there were also many participants halted because of the long distance and cost in journey. Therefore, making ANC more accessible is urgent. A good service attitude is another approach to attract pregnant women since one who had good experiences with ANC could put other women in motion;. (3) mobilise community and family members to encourage ANC during and after pregnancy. Women in poor rural area are more likely to be lack of independence. In other words, they are not used to make decisions towards something important. So, the call of community and support of family would give them courage and belief to overcome the psychological barriers. It would make a big difference if their family members and the community encourage them to accept ANC during pregnancy. (4) HIV screening should continue to be offered at ANC clinics in order to prevent mother-to-child transmission of HIV. The knowledge of the effectiveness and benefits of PMTCT should be improved among women and among their families and other community members.

Although there are important discoveries revealed in this study, there are also limitations. First, the findings may not be generalisable to all the women of childbearing age in the rural area because we only selected women of childbearing age who had pregnancy history in the last 5 years from two towns. Second, due to the mode of survey administration (interviewer-administered face to face), social desirability bias might be introduced. Third, we only focused on the uptake of ANC of the respondents within the whole 5 years and ignored whether they accepted ANC during the most recent pregnancy, so it may overestimate the uptake of ANC. Last, our HIV-related questions were not MTCT or PMCT specific, so future studies should consider HIV-related questions which are more relevant to the concerns and needs of pregnant women.

As a result, the Zhaojue County Maternal and Child Health Hospital gave a publicity to the villagers, therefore, targeted measures were taken to encourage the villagers to conduct ANC.

\section{CONCLUSIONS}

In summary, although the actual uptake of antenatal care among women of childbearing age in this rural minority area is lower than other areas, women in the region have strong intention to ANC. No experience of living outside, higher number of births, not knowing the necessity of ANC during pregnancy and not knowing the government's promotion policies for ANC were associated with lack of ANC uptake. ANC targeting PMTCT in China may need to be more comprehensive and incorporate the cultural, logistic and needs of the population in order to effectively affect this population's utilisation of ANC.

\section{Author affiliations}

${ }^{1}$ Department of Epidemiology, Shandong University School of Public Health, Jinan, China

${ }^{2}$ School of Health Care Management, Shandong University, Jinan, China ${ }^{3}$ School of Public Health and Primary Care, The Chinese University of Hong Kong, Hong Kong, China

${ }^{4}$ Department of TB Control and Prevention, Zhejiang Provincial Center for Disease Control and Prevention, Hangzhou, China

${ }^{5}$ Department of AIDS Control and Prevention, Liangshan Prefecture Center for Disease Control and Prevention, Xichang, China

${ }^{6}$ Department of Epidemiology and Biostatistics \& Global Health Sciences, University of California, San Francisco, California, USA

${ }^{7}$ Zhaojue Maternal and Child Care Service Centre, Zhaojue, China

${ }^{8}$ Zhaojue Zhuhe Central Hospital, Zhaojue, China

${ }^{9}$ Zhaojue Abingluogu Central Hospital, Zhaojue, China

Contributors BL, LN, CW and WM conceived and designed the study. BL, DS and WeW trained interviewers. BY, AE, HZ, WuW and JZ assisted respondents to fill out the questionnaire. BL and DS analysed the data. BL, DS and SW contribute to writing the manuscript. CW and WM critically revised the paper. All authors read and approved the final manuscript.

Funding This study was funded by the Alliance for Health Policy and Systems Research, WHO, Geneva with support from the Norwegian Government Agency for Development Cooperation (Norad), the Swedish International Development Cooperation Agency (Sida) and the UK Department for International Development (DFID). The technical coordination and support was provided by the Department of Maternal Newborn Child and Adolescent Health, WHO Geneva.

Competing interests None declared.

Patient consent for publication Not required.

Ethics approval The study protocol was approved by the Ethical Review Committees of the WHO (RPC587) and Shandong University School of Public Health 
(20130602). Study procedures, voluntary nature of participation, participants' right to withdraw and autonomy of the participants were explained and oral informed consent was obtained from all participants.

Provenance and peer review Not commissioned; externally peer reviewed.

Data availability statement The data used to support the findings of this study are available from the corresponding author upon request.

Open access This is an open access article distributed in accordance with the Creative Commons Attribution Non Commercial (CC BY-NC 4.0) license, which permits others to distribute, remix, adapt, build upon this work non-commercially, and license their derivative works on different terms, provided the original work is properly cited, appropriate credit is given, any changes made indicated, and the use is non-commercial. See: http://creativecommons.org/licenses/by-nc/4.0/.

\section{REFERENCES}

1. World Health Organization. Hiv/Aids. Available: http://www.who.int/ mediacentre/factsheets/fs360/en/ [Accessed 5 Jan 2016].

2. World Health Organization. Antiretroviral drugs for treating pregnant women and preventing HIV infection in infants: recommendations for a public health approach (2010 version) 2010.

3. World Health Organization. PMTCT strategic vision 2010-2015: preventing mother-to-child transmission of HIV to reach the UNGASS and millennium development goals. (2010 version) 2010.

4. Zhang XY, Li M, Feng YB, et al. Meta-Analysis of effect of prevention of mother to child transmission of HIV during 2011-2014 in China. Chin J AIDS STD 2015;21:275-9.

5. Zhu YX, Gong YH, Wang QX, et al. Aids surveillance in injecting drug users in Liangshan, Sichuan, 2010 - 2013. Disease Surveillance 2015;30:395-988.
6. Zhu CH, Zhou YB, Song XX, et al. Review on the influence factors of AIDS epidemic and control in Liangshan Prefecture Sichuan Province of China. Fudan Univ J Med Sci 2015;42:675-9.

7. Wang QX, Gong YH, Nan L, et al. Analysis on the results of sampling survey for HIV infection among rural population in 14 counties of Liangshan prefecture. Modern Preventive Medicine 2015;42:328-50.

8. Gong YH, Wang QX, Nan L, et al. Analysis of HIV infection among rural population aged 15 to 60 in Liangshan Prefecture, Sichuan Province. Chin J Dis Control Prev 2014;18:1132-5.

9. Han $\mathrm{YH}$, Gong $\mathrm{YH}, \mathrm{MJ} \mathrm{M}$, et al. Analysis on the results of comprehensive surveillance on STD/AIDS in Liangshan Prefecture in 2004. J Prev Med Inf 2005;21:316-8.

10. Sun LL. Prevention of mother-to-child transmission of HIV status quo research and influencing factors analysis in Liangshan Prefecture Sichuan province. Sichuan Medical University, 2015.

11. Zhaojue County government. Zhaojue overview. Available: http://zj. Isz.gov.cn/zhaojue/gk/2108281/index.html [Accessed 2 Dec 2015].

12. $\mathrm{Xu} \mathrm{L}$, Zhou H, Wang YC, et al. Factors associated with ANC among Chinese rural women. Maternal \& Child Health Care of China 2003;8:477-8.

13. Fang LW, Lou CH, Gao ES. Study on prenatal care services among married childbearing women in China. Maternal \& Child Health Care of China 2005;20:1424-6.

14. Simkhada B, Teijlingen ERvan, Porter M, et al. Factors affecting the utilization of antenatal care in developing countries: systematic review of the literature. J Adv Nurs 2008;61:244-60.

15. Liu D, Jing J. Current situation and influencing factors of antenatal care service among women in China. Maternal \& Child Health Care of China 2007;22:2868-70.

16. Zeng $\mathrm{H}$, Zhu $\mathrm{H}$, Wang $\mathrm{TY}$, et al. Status quo of antenatal care among women in poor rural areas of Western China. Maternal \& Child Health Care of China 2010;25:4813-5. 